\title{
ANÁLISE DE DISTÂNCIA GENÉTICA ENTRE ACESSOS DO GÊNERO Psidium VIA MARCADORES ISSR ${ }^{1}$
}

\author{
NÁZILA NAYARA SILVA DE OLIVEIRA ${ }^{2}$, ALEXANDRE PIO VIANA ${ }^{3}$, \\ SILVANA SILVA RED QUINTAL ${ }^{4}$, CLAUDIA LOUGON PAIVA ${ }^{5}$, CLÁUDIA SALES MARINHO ${ }^{6}$
}

RESUMO- O objetivo deste trabalho foi avaliar a distância genética entre 37 acessos da espécie cultivada Psidium guajava, L. (goiaba) e de araçás do gênero Psidium do banco de germoplasma da Universidade Estadual do Norte Fluminense (UENF), via marcadores moleculares ISSR. Nos 17 marcadores selecionados, foram obtidas 216 bandas polimórficas. Pelo método de agrupamento UPGMA, houve a formação de cinco principais grupos. Os acessos de araçá da espécie $P$. cattleyanum Sabine, ficaram alocados nos grupos I e II. No grupo II, foi observada, dentro da espécie $P$ cattleyanum, maior proximidade com a goiabeira. No grupo III, ficou alocado o acesso da espécie $P$. guineense $S w$ (araçá-do-campo) e dentre os araçás, foi o que ficou mais próximo da goiaba. Os genótipos de goiabeira ficaram alocados do grupo IV e V, confirmando sua alta divergência. Os marcadores moleculares foram eficientes em estimar a distância genética intra e interespecífica.

Termos para indexação: Psidium spp., distância genética, marcadores ISSR, goiaba, araçá.

\section{ANALYSIS OF GENETIC DISTANCE BETWEEN ACCESS OF THE GENDER Psidium BY ROUTE MARKERS ISSR}

\begin{abstract}
The objective of this study was to evaluate the genetic distance among 37 accessions of cultivated species Psidium guajava, L. (guava) and Araçás to the genus Psidium to the germplasm colection of the Universidade Estadual Norte Fluminense (UENF) by ISSR molecular markers. In the 17 selected markers, 216 polymorphic bands were obtained. By UPGMA method there was the formation of five main clusters. Accessions of araçá species, P. cattleyanum Sabine, were allocated in groups I and II. In group II was observed within the species $P$ cattleyanum, closer to the guava. In group III was allocated the genotypes of the species $P$. guineense $S w$ (araçá-do-campo) and among the araçás, was the most closest to the guava. The guava genotypes were allocated to Group IV and V, confirming their high divergence. Molecular markers were efficient in evaluating intra and interspecific genetic distance for these species.
\end{abstract}

Index terms: Psidium spp., genetic distance, ISSR markers, guava, araça.

\section{INTRODUÇÃO}

Pertencente à Família Myrtaceae, o gênero Psidium está entre os que mais possuem espécies no mundo, cerca de 92 (GOVAERTS et al., 2013). O Brasil é um grande representante dessa diversidade, onde um total de 60 espécies pode ser encontrado, sendo 47 endêmicas (SOBRAL et al., 2013). Alocada neste gênero, a goiabeira (Psidium guajava $\mathrm{L}$., $2 \mathrm{n}=22$ ), originária da região tropical do continente Americano, é praticamente a única espécie amplamente cultivada e consumida em todas as regiões tropicais e subtropicais do mundo, principalmente por seu elevado teor nutritivo, sendo altamente rica em açúcares, sais minerais, vitamina C, licopeno, betacaroteno, fibras, além do sabor e aroma de alta aceitação (RISTERUCCI et al., 2005).

No ano de 2011, o Brasil obteve uma produção de 342.528 toneladas de goiaba, gerando 276.333 milhões de reais, com destaque para as regiões Nordeste e Sudeste, que contribuíram com aproximadamente $88 \%$ da produção nacional (IBGE, 2013). Porém, nas ultimas décadas, essa cultura vem sofrendo vários danos causados pelo fitonematoide Meloidogyne enterolobii ou M. mayaguensis que, segundo Gomes et al. (2011), em associação sinergística com o fungo Fusarium solani (Mart.) Sacc, causam a doença declínio da goiabeira.

${ }_{1}^{1}$ (Trabalho 413-13). Recebido em: 16-10-2013. Aceito para publicação em: 10-09-2014.

${ }^{2}$ Eng. a Agro., D.Sc., Lavras, MG, UFLA/Departamento de Biologia, CEP 37200-000. E-mail: nayara.sancho@hotmail.com

${ }^{3}$ Eng $^{\circ}$. Agro., D.Sc., Professor UENF/CCTA/LMGV, CEP 28015620, E-mail: pirapora@uenf.br

${ }^{4}$ Eng ${ }^{a}$. Agro., D.Sc., Campos dos Goytacazes, RJ, UENF/CCTA/LMGV, CEP 28015620, E-mail: silvanared@hotmail.com ${ }^{5}$ Bióloga, D.Sc. Campos do Goytacazes, RJ, UENF/CCTA/LMGV, CEP 28015620. E-mail: claudialougon@gmail.com.br ${ }^{6} E_{n}{ }^{a}$. Agro.,D.Sc., Professora UENF/CCTA/LMGV, CEP 28015620, E-mail: E-mail marinho@uenf.br 
Alguns estudos, além de confirmarem a suscetibilidade de acessos de goiabeira ao nematoide e ao Fusaruim solani (GOMES et al., 2011; GOMES et al., 2013), também relataram resistência em acessos de araçás da espécie Psidium spp. a $M$. enterolobii (CARNEIRO et al., 2007; ALMEIDA et al., 2009; MIRANDA et al., 2012; MARTINS et al., 2013). Esses trabalhos apontam para a possibilidade de introgressão de alelos de resistência ao germoplasma cultivado, o que demanda trabalhos de pré-melhoramento e melhoramento com essas espécies para o seu maior conhecimento e potencial uso.

Nas ultimas décadas, o uso de marcadores moleculares surgiram como uma alternativa à redução do tempo de execução de um Programa de melhoramento, principalmente quando se trata de plantas perenes, em que se tem procurado associar a informação obtida pelos marcadores a aspectos de diversidade genética e mapeamento de regiões genômicas com influência em características fenotípicas de interesse.

Marcadores ISSR foram utilizados com sucesso para estimar a diversidade genética em grandes culturas, como cevada (HOU et al., 2005) e trigo (SOFALIAN et al., 2008), em espécies do gênero Manihot (SILVA et al., 2011). No gênero Psidium, foram utilizados em espécies de goiaba a araçá (MANI et al., 2011). Este método dispensa o conhecimento prévio do genoma da espécie que se deseja estudar, o que torna sua aplicação vantajosa e promissora em espécies silvestres. Deste modo, o objetivo deste trabalho foi avaliar a distância genética entre acessos da espécie cultivada Psidium guajava L. (goiaba), e de araçás do gênero Psidium provenientes do banco de germoplasma da Universidade Estadual do Norte Fluminense Darcy Ribeiro (UENF), via marcadores moleculares ISSR.

\section{MATERIAL E MÉTODOS}

O presente trabalho foi conduzido a partir da avaliação de 37 indivíduos de Psidium spp., instalados no Colégio Agrícola Antônio Sarlo, em Campos dos Goytacazes, Norte do Estado do Rio de Janeiro. Destes, 27 acessos pertencem ao Banco de germoplasma de araçazeiro e 10 correspondem a genótipos selecionados por Campos et al. (2013) (Tabela 1). Os genótipos de goiabeira são provindos de cruzamentos biparentais controlados, oriundos do Sítio Providência, em Bom Jesus do ItabapoanaRJ (Tabela 1). Os genitores utilizados para os cruzamentos foram obtidos por estudo de diversidade genética via marcadores moleculares RAPD (PESSANHA et al., 2011).
Amostras de folhas jovens de cada acesso foram maceradas em nitrogênio líquido, e cerca de 50 $\mathrm{mg}$ do macerado foram transferidos para tubos de 2 $\mathrm{mL}$ e imersos em nitrogênio líquido para a realização da extração de DNA, conforme adaptações a partir do protocolo básico de Doyle e Doyle (1990). Em cada tubo, foram adicionados $700 \mu$ do tampão de extração pré-aquecido, com um conteúdo de $2 \%$ CTAB, 2, $0 \mathrm{~mol} \mathrm{~L}^{-1} \mathrm{NaCl}, 20 \mathrm{mmol} \mathrm{L}^{-1}$ EDTA, 100 mmol L-1 Tris-HCl ( $\mathrm{pH} 8,0)$, sendo adicionados na solução de 2\% PVP e 2,0\% - mercaptoetanol e então incubados a $65^{\circ} \mathrm{C}$ por 47 minutos, homogeneizando suavemente a cada 10 minutos.

Após a incubação, foram adicionados 600 $\mu \mathrm{L}$ de clorofórmio: álcool isoamílico (24:1), após aproximadamente 1 minuto, a fase orgânica foi separada, realizando-se uma centrifugação a 13.000 rpm por 1 minuto, e o sobrenadante foi transferido para tubos de $1,5 \mathrm{~mL}$ e, em seguida, adicionados dois terços $(500 \mu \mathrm{L})$ do volume total de isopropanol gelado, sendo posteriormente incubados por 30 minutos a $20^{\circ} \mathrm{C}$. Os tubos foram centrifugados a $14.000 \mathrm{rpm}$ por 10 minutos. O sobrenadante foi então descartado, e o precipitado passou por duas etapas de lavagem com $500 \mu \mathrm{L}$ de etanol a $70 \%$, seguidas de centrifugação a $14.000 \mathrm{rpm}$ por 10 minutos. Após o descarte do sobrenadante, o material foi seco em bancada, sendo ressuspendido em $200 \mu \mathrm{L}$ de solução TE (Tris-EDTA - 10 mmol L-1 Tris-HCl, 1 mmol L-1 EDTA, pH 8,0) com RNAse em uma concentração final de 10 ug.mL-1 e incubado em banho-maria a $37^{\circ} \mathrm{C}$ por 30 minutos e então armazenado a $20^{\circ} \mathrm{C}$ até seu uso.

A qualidade do DNA extraído foi verificada em gel de agarose a $\%$, utilizando o marcador High DNA Mass Ladder (Invitrogen ${ }^{\circledR}$, USA). As amostras foram coradas com a mistura e GelRed ${ }^{\mathrm{TM}}$ e Blue Juice (1:1). Das amostras, para a concentração de trabalho de 5 ng $\mu$.L-1, foi realizada a quantificação do material em espectrofotômetro NANODROP $2.000 \mathrm{c}$, com leitura das absorbâncias no comprimento de onda de $260 \mathrm{~nm}$.

As reações de PCR foram realizadas em Termociclador (Veriti 384-well Thermal Cycler Applied Biosystems), com uma fase de desnaturação inicial por 4 minutos, a $94^{\circ} \mathrm{C}$, seguida por 45 ciclos de amplificação: $94^{\circ} \mathrm{C}$ por 1 minuto; $44^{\circ} \mathrm{C}$ a $46^{\circ} \mathrm{C}$ por 1 minuto, conforme o iniciador utilizado; $72^{\circ} \mathrm{C}$ por 3 minutos. Ao término dos ciclos, foi realizada uma extensão final a $72^{\circ} \mathrm{C}$ por 7 minutos.

Cada reação de PCR continha um volume final de $13 \mu \mathrm{L}$ por amostra, contendo 10 ng de DNA, 0,5 uM do iniciador e $0,5 \mathrm{U}$ de Taq DNA Polimerase, $0,02 \mathrm{mM}$ de dNTP e $1,5 \mathrm{mM}$ de cloreto de magnésio e tampão de PCR (1X), sendo realizada a adição de água ultrapura para completar o volume final da reação.

Os produtos de amplificação foram separados por eletroforese em gel de agarose a $2 \%$, com auxílio 
do marcador de 100 pares de base DNA Ladder, utilizado para estimar o tamanho dos fragmentos. A visualização do gel de agarose foi realizada através do sistema de fotodocumentação MiniBis Pro (BioImaging Systems).

Foi realizada uma seleção prévia entre 41 iniciadores, observando os de maior número de bandas polimórficas, tendo ao final um total de 17 marcadores polimórficos (Tabela 2). A partir dessa etapa, após a exclusão das bandas monomórficas de cada marcador, os dados resultantes foram convertidos em matriz numérica com informações sobre o polimorfismo por loco, sendo os dados então analisados com o auxílio do Programa GENES (CRUZ, 2013).

A partir dessas informações, foi calculada a distância genética entre os genótipos estudados ou matriz de dissimilaridade através do Índice de Jaccard. Tal matriz foi utilizada para realizar a análise de agrupamento dos genótipos, por meio de dendrograma através dos métodos hierárquicos UPGMA, Vizinho mais Próximo (SL) e WARD.

A partir desses dados, foi calculado o Coeficiente de Correlação Cofenético (CCC) estresse e distorção, sendo então selecionado o método que melhor explicou a divergência do material (Tabela 3 ).

\section{RESULTADOS E DISCUSSÃO}

Foi observado um nível de polimorfismo elevado, uma vez que, nos 17 marcadores selecionados, foram obtidas 216 bandas polimórficas com a média de 13 por iniciador (Tabela 2). Mani et al. (2011), avaliando a distância genética em diferentes espécies de Psidium spp., obtiveram um total de 234 bandas polimórficas em 31 marcadores ISSR. Silva et al. (2011), avaliando a variabilidade de acessos do gênero Manihot, obtiveram o total de 154 bandas polimórficas em 20 iniciadores avaliados. He et al. (2007) realizaram estudos de diversidade com 100 acessos de batata-doce, coletados na China, Nova Guiné e Indonésia, observando 239 bandas polimórficas, utilizando 14 iniciadores de ISSR, com a média de 17 bandas polimórficas por iniciador.

A partir da matriz numérica, foi possível obter a matriz de distâncias entre indivíduos com a utilização do Índice de Jaccard. O método de agrupamento UPGMA foi selecionado, por apresentar maior Coeficiente de Correlação Cofenético (CCC) (SOKAL; ROHLF, 1962) e menores estresse e distorção, sendo o método que melhor representou a diversidade genética entre os acessos $(0,90$; 5,82 e 0,34 , respectivamente) (Tabela 3). Segundo Mohammad e Prasanna (2003), quanto maior o CCC, menor a distorção no agrupamento dos acessos. Pessanha et al. (2011), com a utilização de marcadores RAPD em acessos de Psidium spp., obtiveram um CCC de 0,92 pelo método UPGMA em relação aos métodos hierárquicos Ward $(0,82)$ e vizinho mais próximo (SL) $(0,90)$.

Considerando o resultado obtido pelo método de agrupamento UPGMA com os 37 acessos, houve a formação de cinco principais grupos claramente definidos (Figura 1).

Os acessos de araçá da espécie Psidium cattleyanum ficaram alocados nos grupos I e II. O primeiro grupo correspondeu aos de número 1 ao 17 . Já no segundo grupo, ficaram os acessos de número 18 ao 26 , sendo o grupo de menor variabilidade, alocando, dentre todos os acessos testados, os de menor distância (19 e 21), com 0,30. É importante ressaltar que, neste grupo, ficaram presentes apenas acessos de araçáuna, coletados na zona urbana do município de Campos dos Goytacazes - RJ, cuja característica fenotípica mais notável é a coloração roxa escura dos frutos, característica que o difere da maioria dos acessos do grupo I que, com exceção dos genótipos 11, 12 e 17, possuem frutos com coloração amarela, além de terem sido coletados em outras cidades da região. Mani et al. (2011), utilizando marcadores moleculares RAPD em acessos de Psidium, na Índia, também separaram em subgrupos diferentes variedades de $P$. cattleyanum.

No grupo II, foi observada, dentro da espécie $P$ cattleyanum, maior proximidade com a goiabeira, o que pode ser promissor, uma vez que foi constatada a resistência desta espécie ao nematoide (CARNEIRO et al., 2007; ALMEIDA et al., 2009; MIRANDA et al., 2012; MARTINS et al., 2013). Tal espécie possui comprovadas diferenças quanto a distância evolutiva em relação à goiaba, principalmente por ser poliploide, sendo constatados diferentes níveis de ploidia, como tetraploide $(2 \mathrm{n}=$ 44) (COSTA; FORNI-MARTINS, 2007), heptaploide (SINGHAL et al., 1980) ou octaploide (ATCHISON, 1947). Ainda assim, pode ser promissora pela alta variabilidade dentro desta, comprovada pela sua separação em grupos claramente definidos, levando à necessidade de maiores esclarecimentos $\mathrm{e}$ conhecimento da estrutura morfológica, citológica e molecular da mesma.

No grupo III, ficou alocado o acesso 27, da espécie $P$. guineense $S w$ (araçá-do-campo) e dentre os araçás, foi o que ficou mais próximo da goiaba (distância média de 0,73 ), o que confirma estudos realizados por Costa e Forni-Martins (2007), que verificaram o mesmo nível de ploidia que a goiaba $(2 n=22)$, podendo facilitar a realização de cruzamentos interespecíficos.

Os genótipos de goiabeira ( $P$. guajava) selecionados por Campos et al. (2013) ficaram alocados do grupo IV e V, confirmando sua alta divergência. Nestes grupos, os genótipos 35 e 37 (Grupo IV) possuem as menores distâncias genéticas $(0,37)$. Essa menor distância, e consequentemente menor variabilidade, pode ser explicada por se tratar de genótipos provenientes de autofecundação. 
Já os genótipos 29, 31 e 33 (Grupo V) são os que apresentaram maiores distâncias na espécie, com média de 0,71 .

Nos grupos IV e V, embora provenham de um programa de melhoramento com relativo grau de seleção, pode ser observada, de um modo geral, alta variabilidade entre os mesmos, o que pode ser favorecido pelo sistema misto de cruzamento, que inclui tanto a autofecundação quanto a polinização cruzada entre plantas da espécie. Corrêa et al. (2011), avaliando a similaridade genética com a utilização de AFLP, obtiveram a formação de diferentes agrupamentos em acessos de goiaba coletados em diferentes regiões do Brasil. Sanabria et al. (2006), com a utilização de 74 marcadores polimórficos de RAPD, reportaram também alta diferenciação genética $(0,355)$ entre 53 acessos de goiabeiras colombianas.

No grupo V, o genótipo 33, por ter maior distância genética entre os demais, poderia ser promissor em cruzamentos com os genótipos 35 ou 37 (grupo IV), podendo gerar indivíduos com maior produção, aliados a um maior teor de sólidos solúveis e de vitamina $\mathrm{C}$, de acordo com estudos realizados por Campos et al. (2013). Outra opção de cruzamento promissor seria entre os genótipos 29 e 31; 36 e 31(Grupo V), pois além de possuírem alta divergência, poderiam proporcionar frutos grandes, com maior peso de polpa e de placenta, ideias para a indústria de alimentos.

TABELA 1-Acessos de Psidium spp., localizados na Unidade de Pesquisa da UENF, Campos dos Goytacazes, RJ.

\begin{tabular}{|c|c|c|c|c|}
\hline Acessos & Nome comum & Características & Espécie & Procedência \\
\hline $\begin{array}{l}1,3,6,7,8,9,10,13 \\
15,16\end{array}$ & Araçá amarelo & Fruto amarelo & P. cattleyanum & A \\
\hline $2,4,5$ & Araçá amarelo & $\begin{array}{l}\text { Fruto amarelo; } \\
\text { Resistente }^{1}\end{array}$ & P. cattleyanum & B \\
\hline 14 & Araçá-coroa & $\begin{array}{l}\text { Fruto amarelo; } \\
\text { Resistente }^{1}\end{array}$ & P. cattleyanum & A \\
\hline $\begin{array}{l}11,12,17,18,19,20 \\
21,22,23,24,25,26\end{array}$ & Araçaúna & $\begin{array}{l}\text { Fruto roxo escuro; } \\
\text { Resistente }^{1}\end{array}$ & P. cattleyanum & B \\
\hline 27 & Araçá do campo & Fruto amarelo & P. guineense & $\mathrm{C}$ \\
\hline $\begin{array}{l}28,29,30,31,32,33, \\
34,35,36,37\end{array}$ & Goiaba & Cor da polpa vermelha ${ }^{2}$ & P. guajava & $\mathrm{D}$ \\
\hline
\end{tabular}

${ }^{1}$ meio-irmãos resistentes ao nematoide; ${ }^{2}$ Genótipos de goiabeira oriundos de cruzamentos biparentais; A -São João da Barra, RJ; BCampos dos Goytacazes, RJ; C- Itaboraí, RJ; D- Bom Jesus do Itabapoana, RJ.

TABELA 2- Iniciadores ISSR utilizados para a caracterização molecular em acessos de Psidium spp.

\begin{tabular}{cccc}
\hline Primer & Sequência & T.A. & Número de bandas \\
\hline 1 & $(\mathrm{GA})_{8} \mathrm{YC}$ & $50^{\circ} \mathrm{C}$ & 11 \\
2 & $(\mathrm{AG})_{8} \mathrm{YC}$ & $50^{\circ} \mathrm{C}$ & 12 \\
3 & $\mathrm{~T}(\mathrm{GA})_{8}$ & $50^{\circ} \mathrm{C}$ & 11 \\
4 & $(\mathrm{GA})_{8} \mathrm{C}$ & $50^{\circ} \mathrm{C}$ & 13 \\
5 & $\mathrm{TA}(\mathrm{CAG})_{4}$ & $50^{\circ} \mathrm{C}$ & 13 \\
6 & $(\mathrm{CT})_{8} \mathrm{GC}$ & $40^{\circ} \mathrm{C}$ & 12 \\
7 & $(\mathrm{TG})_{8} \mathrm{GG}$ & $44^{\circ} \mathrm{C}$ & 14 \\
8 & $(\mathrm{GAA})_{6} \mathrm{AA}$ & $44^{\circ} \mathrm{C}$ & 13 \\
9 & $(\mathrm{AG})_{8} \mathrm{~T}$ & $46^{\circ} \mathrm{C}$ & 12 \\
10 & $(\mathrm{GA})_{8} \mathrm{YT}$ & $46^{\circ} \mathrm{C}$ & 16 \\
11 & $(\mathrm{GACA})_{4}$ & $46^{\circ} \mathrm{C}$ & 12 \\
12 & $\mathrm{HVH}(\mathrm{TG})_{7}$ & $46^{\circ} \mathrm{C}$ & 14 \\
13 & $(\mathrm{CA})_{8} \mathrm{~T}$ & $46^{\circ} \mathrm{C}$ & 14 \\
14 & $(\mathrm{CA})_{8}^{\mathrm{a}}$ & $48^{\circ} \mathrm{C}$ & 13 \\
15 & $(\mathrm{CA})_{8} \mathrm{G}$ & $50^{\circ} \mathrm{C}$ & 13 \\
16 & $(\mathrm{TC})_{8} \mathrm{G}$ & $46^{\circ} \mathrm{C}$ & 10 \\
17 & $(\mathrm{GGAGA})_{3}$ & $46^{\circ} \mathrm{C}$ & \\
\hline
\end{tabular}

TA: Temperatura de Anelamento $\left({ }^{\circ} \mathrm{C}\right)$ 
TABELA 3- Coeficiente de Correlação Cofenético (CCC), estresse e distorção dos Métodos Ward, UPGMA e Vizinho mais próximo (SL).

\begin{tabular}{cccc}
\hline & WARD & UPGMA & SL \\
CCC & $0,80^{* *}$ & $0,90^{* *}$ & $0,85^{* *}$ \\
Estresse (\%) & - & 5,82 & 15,8 \\
Distorção (\%) & - & 0,34 & 26,83 \\
\hline
\end{tabular}

** Significativo ao nível de $1 \%$, pelo teste $\mathrm{t}$.

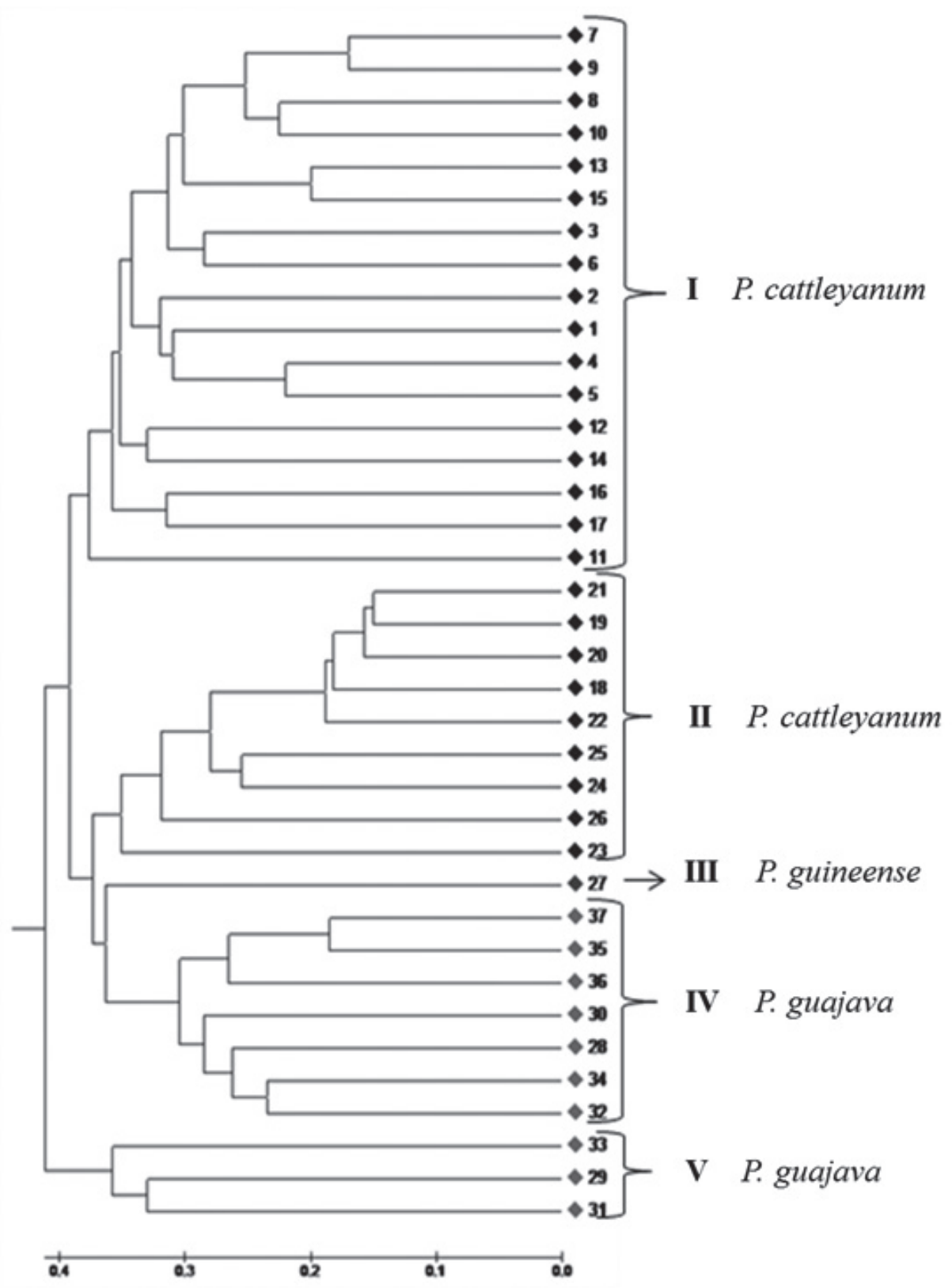

FIGURA 1- Dendrograma obtido pelo método hierárquico UPGMA e complemento aritmético do Índice de Jaccard em 37 indivíduos do gênero Psidium . 


\section{CONCLUSÕES}

Os acessos de araçá alocados nos grupos II e III possuem maior proximidade com a goiaba, o que demanda maiores esclarecimentos e conhecimentos sobre a espécie e seu potencial uso em Programas de Melhoramento, visando à resistência ao Nematoide e ao Fusarium.

Foi possível observar grande variabilidade entre os genótipos de goiabeira, o que possibilita a realização de cruzamentos com genótipos superiores de alta divergência.

Os marcadores moleculares foram eficientes em estimar a distância genética intra e interespecífica.

\section{REFERÊNCIAS}

ALMEIDA, E.J.; SANTOS, J.M.; MARTINS, A.B.G. Resistência de goiabeiras e araçazeiros a Meloidogyne mayaguensis. Pesquisa Agropecuária Brasileira, Brasília, v.44, n.4, p.421-423, 2009.

ATCHISON E. Chromosome numbers in the Myrtaceae. American Journal of Botany, Columbus, v.34, n.3, p.159-164, 1947.

CAMPOS, B.M.; VIAVA, A. P.; QUINTAL, S. S. R.; GONÇALVES, L. S. A.; PESSANHA, G. O.P. Quantificação da divergência genética entre acessos de goiabeira por meio da estratégia WARD - MLM. Revista Brasileira de Fruticultura, Jaboticabal, v.35, n.2, p.087-094, 2013.

CARNEIRO, R.M.D.G.; CIROTTO, P.A.; QUINTANILHA, A.P.; SILVA, D.B.; CARNEIRO, R.G. Resistance to Meloidogyne mayaguensis in Psidium spp. accessions and their grafting compatibility with $P$. guajava cv. Paluma. Fitopatologia Brasileira, Brasília, v.32, n.4, p.281284, 2007.

CORRÊA, L.C.C.; SANTOS, C. A. F.; LIMA, G. P. P.; RODRIGUES, M. A.; COSTA, T. P. P. Similaridade genética entre acessos de goiabeiras e araçazeiros baseada em marcadores moleculares AFLP. Revista Brasileira de Fruticultura, Jaboticabal, v.33, n.3, p.859-867, 2011.

COSTA, I. R.; FORNI-MARTINS, E. R. Karyotype analysis in South American species of Myrtaceae. Botanical Journal of the Linnean Society, London, v.155, n.4, p.571-580, 2007.
CRUZ, C. D. (2013) GENES - a software package for analysis in experimental statistics and quantitative genetics. Acta Scientiarum. Agronomy, Maringá, v.35, n.3, p.271-276, 2013.

DOYLE, J. J.; DOYLE, J. J. Isolation of plant DNA from fresh tissue. Focus, Gaithesburg, v.12, n.1, p.13-15, 1990.

GOLDBLATT, P.; JOHNSON, D. E. Index to plant chromosome numbers 1986-1987. Monographs in Systematic Botany from the Missouri Botanical Garden, St Louis, v.30, p.1-243, 1990.

GOMES, V.M.; SOUZA, R.M.; MUSSI-DIAS, V.; SILVEIRA, S.F.; DOLINSKI, C. Guava decline: a complex disease involving Meloidogyne mayaguensis and Fusarium solani. Journal of Phytopathology, Berlin, v.159, n.1, p.45-50, 2011.

GOMES, V. M.; SOUZA, R. M.; SILVEIRA, S. F.; ALMEIDA A. M. Guava Decline: Guava decline: effect of root exudates from Meloidogyne enterolobiiparasitized plants on Fusarium solani in vitro and on growth and development of guava seedlings under controlled conditions. Journal of Plant Pathology, Bari, v.137, n.2, p. 393-401, 2013.

GOVAERTS, R.; SOBRAL, M.; ASHTON, P.; BARRIE, F.; HOLST, B. K.; LANDRUM, L.; MATSUMOTO, K.; MAZINE, F. F.; LUGHADHA, E. N.; PROENÇA, C.; SOARESSILVA, L. H.; WILSON, P. G.; LUCAS, E. World check-list of Myrtaceae. Kew: Royal Botanic Gardens, 2013. Disponível em: < http://apps.kew.org/wcsp/ $>$. Acesso em: 10 ago. 2013.

HE, X.; LIU, Q.; ISHIKI, K.; ZHAI, H.; WANG, Y. ISSR analysis of genetic diversity and relationships among sweet potato (Ipomoea batatas) landraces in China. Plant Genetics and Breeding, v.150, n.1, p.35-41, 2007.

HOU, Y.C.; YAN, Z.H.;WEI, Y.M.; ZHENG, Y. L. Genetic diversity ib barley from west China based on RAPD and ISSR analysis. Barley Genetics Newsletter, v.35, p.9-12, 2005.

IBGE- Instituto Brasileiro de Geografia e Estatística. Produção agrícola municipal 2011. Disponível em: < http://www.ibge.gov.br/home/>. Acesso em: 15 jul. 2013. 
MANI, A.; MISHRA, R.; THOMAS, G. Elucidation of diversity among psidium species using morphological and SPAR methods. Journal of Phytology, Allahabad, v.3, n.8, p.53-61, 2011.

MARTINS, L. S.; MUSSER, R. S.; SOUZA, A. G.; RESENDE, L. R.; MALUF, W. R. Parasitismo de Meloidogyne enterolobii em espécies de Myrtaceae. Revista Brasileira de Fruticultura, Jaboticabal, v. 35, n. 2, p. 477-484, 2013.

MIRANDA, G. B.; SOUZA, R. M.; GOMES, V. M.; FERREIRA, T. F.; ALMEIDA, A. M. Avaliação de acessos de Psidium spp. quanto à resistência a Meloidogyne enterolobii. Bragantia, Campinas, v.71, n.1, p.52-58, 2012.

MOHAMMAD, S.A.; PRASANNA, B.M. Analysis of genetic diversity in crop plants- Salient statistical tools and considerations. Crop Science, Madison, v.43, p.1235-1248, 2003.

PESSANHA, P. G. O.; VIANA, A. P.; AMARAL JÚNIOR, A. T.; SOUZA, R. M.; TEXEIRA, M. C.; PEREIRA, M. G. Avaliação da diversidade genética em acessos de Psidium spp. via marcadores moleculares RAPD. Revista Brasileira de Fruticultura, Jaboticabal, v.33, n.1, p.129-136. 2011 .

RISTERUCCI, A.M.; DUVAL M. F..; ROHDE, $\mathrm{W}$; BILLOTTE, N. Isolation and characterization of microsatellite loci from Psidium guajava $L$. Molecular Ecology Notes, Vancouver, v.5, p.745748. 2005.

SANABRIA, H. L.; GARCÍA, M.; DÍAZ, H.; MUÑZ, J.E. Caracterización molecular con marcadores RAM de arboles nativos de Psidium guajava (guayaba) en el Valle del Cauca. Acta Agronomica, Palmira, v.55, n.1, p.27-38, 2006.
SILVA, K. V. P.; ALVES, A. A. C.; MARTINS, M. I. G.; MELO, C. A. F.; CARVALHO, R. Variabilidade genética entre acessos do gênero Manihot por meio de marcadores moleculares ISSR. Pesquisa Agropecuária Brasileira, Brasília, v.46, n.9, p.10821088, 2011.

SINGHAL, V. K.; GILL, B. S.; BIRR, S. S. Chromosome number reports LXVII. Taxon, Utrecht, v.29, n.2/3, p.355-357, 1980.

SOBRAL, M.; PROENÇA, C.; SOUZA, M.; MAZINE, F.; LUCAS, E. Myrtaceae: lista de espécies da Flora do Brasil. Rio de Janeiro: Jardim Botânico do Rio de Janeiro, 2013. Disponível em:

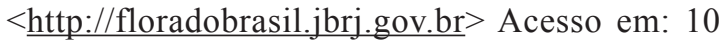
ago. 2013.

SOFALIAN, O.; CHAPARZADEH, N.; JAVANMAR,A.; HEJAZI, M. S. Study the genetic diversity of wheat landraces from northwest of Iran based on ISSR molecular markers. International Journal of Agriculture and Biology, Faisalabad, v.10, n.4, p.465-468, 2008.

SOKAL, R. R.; ROHLF, F. J. The comparison of dendrograms by objetive methods. Taxonomy, Netherlands, v.11, n.2, p.33-40, 1962.

VALDES-INFANTE, J.; RODRIGUEZ, N. N.; BECKER, D.; VELÁZQUEZ, B.; SOURD, D.; ESPINHOSA, G.; ROHDE, W. Microssatelite Characterization of guava (Psidium guajava L) germoplasm collection in Cuba. Cultivos Tropicales, La Habana, v.28, n.3, p.61-67, 2007.

WILSON, P. G.; O’BRIEN, M. M.; GADEK, P.A.; QUINN, C. J. Relationships within Myrtaceae sensu lato based on amatk phylogeny. American Journal of Botany, Ithaca, v.88, n.11, p.2013-2025, 2001. 